\title{
Robotika i neurofizioterapija nakon moždanog udara
}

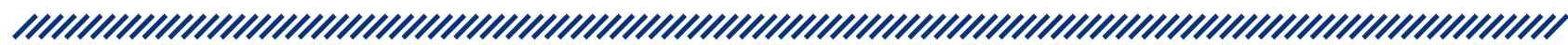

1 Lana Erjavec

1 Kristina Delaš

1 Gordana Grozdek Čovčić

1 Mirjana Telebuh

1 Zdravstveno veleučilište Zagreb

\section{Sažetak}

"

Većina studija o robotima $u$ neurorehabilitaciji usredotočena je na njihovu učinkovitost dajući kontroverzne rezultate. Neka istraživanja ukazuju da pacijenti nakon moždanog udara koji primaju robotski trening potpomognutog hoda u kombinaciji s fizioterapijom postižu samostalno hodanje lakše od onih koji nisu imali trening potpomognut robotom. Međutim, neka klinička ispitivanja govore u prilog manualnoj terapiji. Kritičari novijih tehnoloških pristupa ističu premali broj istraživanja učinkovitosti robotskih uređaja, visoku cijenu, nisku razinu edukacije terapeuta s robotskim uređajima, slabu dostupnost te manjak sigurnosti kod nekih modela. Istraživanja pokazuju kako roboti i ostala tehnološka sredstva koja omogućuju brže kretanje tijela nemaju ciljano djelovanje bez fizioterapeuta specijaliziranog u svojem području. S druge strane, motiviranost pacijenata, mogućnost ponavljanja pokreta, kraće trajanje terapije, dinamičnost, sposobnosti modifikacije raznih parametara, objektivnost te velika mogućnost njihova daljnjeg razvoja prednosti su suvremenih tehnologija. Roboti, kao i svi tehnološki uređaji trebali bi se promatrati kao oruđe u rukama fizioterapeuta. Robot može ublažiti sve intenzivne faze tjelesne rehabilitacije, čime se fizioterapeut može usredotočiti na funkcionalnu rehabilitaciju tijekom individualnog treninga kao i nadzor nad nekoliko pacijenata $u$ isto vrijeme tijekom terapije uz pomoć robota. Ovim pristupom optimizira se stručnost i vrijeme fizioterapeuta, istodobno povećavajući učinkovitost rehabilitacijskog programa. Trenutačni broj istraživanja nije dovoljan za definitivni zaključak koji može govoriti za suvremene tehnologije ili protiv njih, ali uz kombiniranu primjenu manualne terapije mogu pridonijeti bržem oporavku funkcije te većoj kvaliteti pacijentova života.

Ključne riječi: moždani udar, rehabilitacija, suvremena tehnologija, robotika

Datum primitka: 4.6.2019.

Datum prihvaćanja: 1.9.2019.

DOI: $10.24141 / 1 / 5 / 2 / 9$

Adresa za dopisivanje: Gordana Grozdek Čovčić

E-mail: gordana.grozdek-covcic@zvu.hr T: +385914595934 


\section{Uvod}

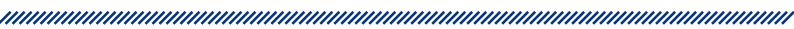

Moždani udar ili cerebrovaskularni inzult može se definirati kao naglo nastali neurološki poremećaj koji je uzrokovan poremećajem cirkulacije u mozgu. Nastali poremećaj cirkulacije u mozgu dovodi do nedovoljne opskrbe dijela mozga kisikom i hranjivim tvarima. Zbog nedostatka kisika i hranjivih tvari dolazi do oštećenja i odumiranja živčanih stanica u zahvaćenim dijelovima mozga. Oštećenje i odumiranje živčanih stanica manifestira se oštećenjem funkcija kojima ti dijelovi mozga upravljaju. 0 mjestu gdje je cirkulacija poremećena ovisi i oštećenje funkcije, koje može biti privremeno ili trajno, može dovesti do limitiranih aktivnosti svakodnevnog života i restrikcije u participaciji u svakodnevnom životu. ${ }^{1}$

Moždani udar može biti ishemijski, uzrokovan ugruškom koji začepi arteriju i onemogući protok krvi kroz nju; ili hemoragijski, uzrokovan puknućem krvne žile i prodiranjem krvi u okolno tkivo. Ishemijski moždani udari mogu biti posljedica tromboze odnosno stvaranje ugruška u oštećenoj arteriji koja mozak opskrbljuje krvlju ili embolije odnosno otkidanje komadića ugruška koji je nastao na drugom mjestu, a krvnom strujom doputuje i začepi moždanu arteriju.

Danas moždani udar predstavlja globalnu epidemiju koja ugrožava živote, zdravlje i kvalitetu života. Procjenjuje se da u svijetu ima oko 26 milijuna ljudi koji su preživjeli neki od oblika moždanog udara te nastavili živjeti s nekim od onesposobljenja koje donosi preživljavanje. Gotovo dvije trećine ljudi koji prežive moždani udar suočava se s nekim oblikom deficita u obliku pokretljivosti, a više od $30 \%$ preživjelih ne može samostalno hodati oko šest mjeseci nakon moždanog udara. ${ }^{2}$

Budući da je postotak ljudi s nekim oblikom oštećenja nakon moždanog udara velik, konvencionalna fizioterapija bila je primorana kroz svoju povijest razviti brojne manualne tehnike unutar koncepata kao što su Bobath, PNF za vraćanje funkcionalnog pokreta i poboljšanje kvalitete života pacijenata. ${ }^{3}$ Paralelno s razvitkom velikog broja manualnih tehnika ušli smo u moderno tehnološko doba gdje se dogodio veliki razvoj tehnologije koja je $s$ vremenom pronašla svoje mjesto u rehabilitaciji preživjelih osoba nakon moždanog udara. Tako danas u procesu rehabilitacije osoba koje su preživjele moždani udar možemo naći primjenu robo- tike i virtualne realnosti. Cilj je u rehabilitaciji kod velikog broja preživjelih osoba povratak balansa, hod te povratak aktivnostima svakodnevnog života . Budući da su nakon moždanog udara balans i hod najčešći problemi preživjelih osoba, istražili smo što literatura kaže o primjeni suvremenih tehnologija u rehabilitaciji hoda i balansa.

\section{Razrada}

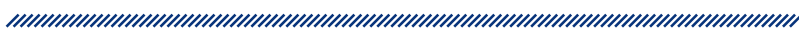

Robotski asistiran trening hoda (RATH ili engl. RAGT) primjenjuje se od 1980. godine za pomoć pri hodu pacijenata s disfunkcijom u pokretu uzrokovanim neurološkim poremećajima ${ }^{4}$. Ovaj tretman temelji se na principu body weight supported treadmill (BWSTT) i postiže se funkcionalno motoričko učenje hoda kroz repetitivno ponavljanje faza hoda. ${ }^{5}$ Ponavljanje istog pokreta omogućuje živčanom sustavu da stvori bolju komunikaciju središnjega živčanog sustava i periferije. ${ }^{6}$

Rehabilitacija osoba nakon moždanog udara po principu BWSTT sastoji se od jednog i/ili dvaju fizioterapeuta koji izvode facilitaciju željenog pokreta, dok je pacijent na traci gdje mu robot daje ili potpuno rasterećenje njegove težine tijela ili mu dopušta doziranu težinu tijela na donje ekstremitete. BWSTT se u usporedbi s konvencionalnim oblikom rehabilitacije hoda pokazao boljim zbog toga što pacijentu omogućava da hoda duže, da radi više koraka te dolazi do većeg broja ponavljanja ciklusa hoda. ${ }^{7}$ Međutim, BWSTT ima i svojih negativnih strana. među kojima je i ta da može zahtijevati velike napore terapeuta, npr. u određenim situacijama da bi se pravilno izveo pokret mogu biti potrebna dva i više terapeuta. $^{8}$

Rehabilitacijski roboti definiraju se kao programirani, multifunkcionalni elektromehanički uređaji koji su dizajnirani da prenose vanjsku silu na ekstremitete pacijenta tijekom izvođenja zadataka kao što je hodanje. U fizioterapiji ih možemo podijeliti na egzoskeletne i endoskeletne. Egzoskeletni roboti, kao što su Lokomat, AutoAmbulator i LOPES, vezani su paralelno za donji ekstremitet pacijenta te tako pomiču sve zglobove u ekstremitetu. Egzoskeletni roboti najčešće su postavljeni iznad pomične trake. Endoskeletni roboti vezani su za krajnji dio ekstremiteta te pomiču samo stopala ili dlanove. 
Virtualna realnost (VR) jest platforma koja omogućava stvaranje virtualnog svijeta za pacijenta prilikom terapije. Unutar tog virtualnog svijeta pacijent obavlja zadatke koji su dio rehabilitacije. VR može biti samostalan izbor rehabilitacije ili dodatni sadržaj uz rehabilitaciju robotikom.

Kao i sve na svijetu, tako i novije tehnologije imaju prednosti i mane. Neke su od prednosti veća motiviranost pacijenta, pogotovo onih mlađih generacija, dinamičnost programa, kraće trajanje rehabilitacije $u$ cijelosti, veća objektivnost, budući da sada napredak vidimo ipak prikazan na robotu, mogućnost modifikacije velikog broja parametara (npr. na Lokomatu je moguće prilagoditi dužinu ili širinu koraka). Uz prednosti dolaze i mane, a kod novijih tehnologija to su mali broj provedenih istraživanja, što ne čudi budući da su roboti i virtualna realnost prisutni tek u posljednjih 15 do 10 godina. Visoka cijena samih uređaja, a isto tako njihova isplativost kada se pogleda koliko zauzimaju prostora, koliko trebaju struje te da je potreban barem jedan educirani terapeut sljedeća su mane suvremenih tehnologija. Budući da su novije tehnologije tek počele biti prisutne u obliku rehabilitacije ne čudi da je mali broj terapeuta educiran za rad s njima. Kada se govori o rehabilitaciji nakon moždanog udara, najčešći je cilj poboljšanje balansa i trening hoda s pacijentom, a kada je riječ o tretmanu Lokomatom, nedostatak je što se rehabilitacija odvija samo u sagitalnog ravnini te u zdjelici i trpu nema potrebne rotacije koja se događa u normalnom hodu.

$\mathrm{U}$ ovom radu prikazano je nekoliko istraživanja koja se bave usporedbom konvencionalne i terapije suvremenim tehnologijama. Fisher i suradnici 2011. imali su za cilj istražiti postoji li statistički značajna razlika između konvencionalne fizioterapije i RAGT rehabilitacije (robotski asistiran trening hoda RATH ili engl. RAGT). U istraživanju je sudjelovalo 20 osoba s hemiparezom nakon moždanog udara. Kriteriji koji su morali biti zadovoljeni da bi ušli u istraživanje bili su: dob između 18 i 80 godina te da nemaju ortopedskih problema, neki iz spektra mišićnih bolesti, srčane probleme, aktivne upale, da nisu teži od $135 \mathrm{~kg}$ i da nisu trudni. Nakon eliminacije sudionika ostalo je 20 pacijenata koji su zadovoljili sve kriterije. Sudionici su prošli inicijalne testove koji su se sastojali od testa hoda na $8 \mathrm{~m}$, trominutnog testa hoda te Tinetti procjene balansa. Nakon što su rezultati inicijalnog mjerenja bili zabilježeni sudionici su nasumično podijeljeni u dvije skupine po 10 sudionika. Prva skupina primila je konvencionalnu fizioterapiju 24 puta u trajanju po jedan sat. Terapiju je provodio tim koji se sas- tojao od fizioterapeuta i dva fizioterapeutska asistenta. Terapija se sastojala od vježbi istezanja, vježbi snage za donje ekstremitete te treninga hoda uz pomagala. Uz terapiju je fizioterapeut primjenjivao i neurofacilitacijske tehnike kada su bile potrebne. Druga skupina primila je terapiju 24 puta u trajanju od sat vremena. Njihova terapija sastojala se od pola sata konvencionaIne terapije kao i kod prve skupine, a drugih pola sata primjenjivao se RAGT pristup na HelathSouth Autoambulatoru. Nakon odrađene 24 terapije svi su sudionici ponovno prošli test hoda na $8 \mathrm{~m}$, trominutni test hoda te Tinetti procjenu balansa. Rezultati su pokazali da su zasebno obje skupine došle do statistički značajnog poboljšanja u funkciji, dok nema statistički značajne razlike između kontrolne i RAGT skupine. Takvi nam rezultati ukazuju kako konvencionalna i RAGT terapija na kraju rehabilitacije daju podjednak napredak. Jedina je razlika između oblika terapije činjenica da je u konvencionalnoj terapiji potreban znatno veći broj fizioterapeuta nego što je to kod RAGT pristupa. ${ }^{3}$

U pregledanom radu Hidlera i suradnika iz 2009. godine cilj je bio istražiti postoji li razlika, u korist terapiji robotom, u primjeni rane rehabilitacije hoda robotom i konvencionalnom fizioterapijom kod osoba koje su preživjele moždani udar. U istraživanju su sudjelovale ukupno 72 osobe koje su preživjele moždani udar. Kriteriji koje su morali zadovoljiti bili su hemipareza uzrokovana ishemijskim ili hemoragijskim moždanim udarom prije kojeg nije bilo prijašnjih moždanih udara, morali su imati više od 18 godina, mogućnost hoda na $5 \mathrm{~m}$ bez asistencije te brzinu hoda između 0,1 i 0,6 $\mathrm{m} / \mathrm{s}$ te nisu smjeli primati nikakav drugi oblik fizikalne terapije za donje ekstremitete. Kriteriji koji su dodatno isključivali sudionike bili su osteoporoza, problemi sa srcem, nekontrolirana hipertenzija, lezija na malom mozgu koja je posljedica moždanog udara, nekontrolirani napadaji, amputacija donjih ekstremiteta te simptomi depresije. Svi ispitanici koji su zadovoljili kriterije podijeljeni su u dvije skupine prema brzini svojeg hoda. Te dvije skupine randomizirano su ponovno podijeljene u dvije nove skupine od kojih je jedna primala konvencionalni oblik fizioterapije, a druga terapiju Lokomatom. Terapije su se odvijale tri puta tjedno kroz osam do deset tjedana. Ukupno je bilo 24 terapije u trajanju od 1,5 sata. Konvencionalna terapija uključivala je facilitaciju koju je provodio fizioterapeut, cilj je bio poboljšati hod, brzinu hoda, poboljšati posturalnu stabilnost i simetriju tijela. Svaki tretman prilagođavao se osobi prema individualnim mogućnostima. Terapija Lokomatom započela je tako da se robot prilagodio 
na pacijenta, nakon čega je mogla započeti terapija. Cilj je bio da pacijenti pomiču svoje donje ekstremitete pokušavajući smanjiti pomoć Lokomata. Prva terapija bila je takva da je $40 \%$ tjelesne težine pacijenta nosio robot tako da bi se pacijenti mogli usredotočiti na hod. Početne brzine hoda su bile do $1,5 \mathrm{~km} / \mathrm{h}$, a kako je terapija išla dalje brzina hoda i opterećenje pacijentovom težinom se mijenjalo u skladu s pacijentovim napretkom. Mjerenja su se radila prije početka programa, nakon 12 tretmana, ponovno nakon sva 24 tretmana te tri mjeseca nakon prestanak terapije. Prva mjerenja sastojala su se od mjerenja brzine hoda na $5 \mathrm{~m}$ i mjerenja udaljenosti prijeđene u šest minuta hoda.

Drugo mjerenje uključivalo je Berg Balance test, Functional ambulation categories - FAC, NIH stroke scale, Motor assessment scale, Rivermead Mobility Indeks, SF-36 Health Survey. ${ }^{9-11}$ Cijelu terapiju ukupno je prošlo 63 pacijenta, od kojih je 33 primalo trening Lokomatom, a ostalih 30 konvencionalnu fizioterapiju. Zaključak je ovog istraživanja, koje je uspoređivalo konvencionalnu terapiju s terapijom Lokomatom, da primjena konvencionalne fizioterapije u rehabilitaciji daje bolje rezultate i veća poboljšanja u postizanju brzine hoda i duljine hoda kod osoba sa srednje teškim i teškim oštećenjima nakon unilateralnoga moždanog udara. Skupina koja je primala terapiju Lokomatom pokazala je statistički značajno poboljšanje u svim mjerenim segmentima, ali konvencionalna terapija pokazala se kao bolji izbor za ovu skupinu bolesnika. ${ }^{12}$

Jedna od limitacija Lokomata jest činjenica da pacijentu onemogućava kretnje u zdjelici i trupu. Lokomat snažno pritišće pacijentovu zdjelicu u frontalnu ravninu, a u sagitalnoj ravnini ima stražnji jastučić s prilagodljivim trakama koje onemogućuju pokretanje. Takva postura na Lokomatu onemogućava pokretljivost zdjelice prilikom hoda. Ograničenja u rotaciji zdjelice i prijenosu težine na noge mogu dovesti do smanjene pokretljivosti u trupu ${ }^{12}$ te poremećaja medio-lateralne stabilnosti ${ }^{13}$ koji su prijeko potrebni za trening hoda. Restrikcije koje daje Lokomat mogu poremetiti i uzorke ubrzavanja donjih ekstremiteta. Istraživanje navodi kako pacijenti koji tijekom hoda uz asistenciju Lokomata mogu imati abnormalno ubrzanje i usporavanje od prestanka kontakta prstima do inicijalnog kontakta petom u fazama hoda. ${ }^{14}$ Druga istraživanja navode da zdravi sudionici istraživanja imaju veću pokretljivost zdjelice u frontalnoj i sagitalnoj ravnini kada hodaju samostalno na traci nego kada hodaju uz asistenciju robota. ${ }^{8}$ Još je jedna od limitacija hoda uz Lokomat zamah rukama prilikom hoda na Lokomatu. Budući da se uređaj stavlja na paci- jenta, pokraj svakog kuka pacijent ima otprilike $14 \mathrm{~cm}$ robota na sebi, što onemogućava normalan zamah rukama prilikom hoda. ${ }^{15}$

U istraživanju koji su proveli Morone i suradnici 2011. godine cilj je bio pronaći koji pacijenti mogu postići najveću dobrobit od terapije uz primjenu robotike. $U$ istraživanju je sudjelovalo 48 osoba koje su imale neko od motoričkih oštećenja i smanjenu funkciju pri hodu nakon moždanog udara. Svih 48 sudionika bilo je podijeljeno u skupine, jedna se klasificirala kao skupina $s$ visokim motoričkim sposobnostima, a druga s nižim. Svi sudionici imali su dvije terapije dnevno, pet dana u tjednu u trajanju od tri mjeseca. Oni koji su bili podvrgnuti robotskoj terapiji dobili su kombinaciju robotike i konvencionalnog treninga hoda, a druga je skupina primala samo konvencionalnu terapiju. Rezultati su se gledali nakon provedenih testova Functional ambulation categories - FAC, Rivermead Mobility Indeks - RMI i 6-minutnog testa hoda. Skupina koja je u početku imala nižu motoričku sposobnost nakon izlaznih testiranja pokazala je statistički značajan napredak, dok se kod skupine s većim motoričkim funkcioniranjem pokazao jednak napredak i u konvencionalnoj i robotskoj terapiji. Ono što možemo zaključiti iz ovih podataka, kao i autori, jest da kombinacija robotike i konvencionalne terapije može biti učinkovitija nego samo konvencionalna terapija kod pacijenata koji pokazuju veće motoričko oštećenje. ${ }^{16}$

Većina studija o robotima za rehabilitaciju usredotočena je na njihovu učinkovitost dajući kontroverzne rezultate. U svojem istraživanju Mehrholz i Pohl ${ }^{17}$ pokazali su da pacijenti koji primaju robotski trening potpomognutog hoda u kombinaciji s fizioterapijom postižu samostalno hodanje lakše nego pacijenti koji nisu imali trening potpomognut robotom. Međutim, klinička ispitivanja ${ }^{9,18}$ sugeriraju da manualna terapija može biti učinkovitija od robotskog hoda u subakutnoj i kroničnoj fazi u rehabilitaciji nakon moždanog udara. 


\section{Zaključak}

Primjena suvremene tehnologije ne smije zamijeniti neurofizioterapiju koju provodi fizioterapeut. Roboti, kao i svi tehnološki uređaji, moraju se promatrati kao oruđe u rukama fizioterapeuta i nikad se ne mogu primjenjivati zasebno. ${ }^{19}$ Robot može ublažiti sve intenzivne faze tjelesne rehabilitacije, čime se fizioterapeut može usredotočiti na funkcionalnu rehabilitaciju tijekom individualnog treninga, a opet može nadzirati nekoliko pacijenata u isto vrijeme tijekom terapije uz pomoć robota. Ovim pristupom optimizira se stručnost i vrijeme fizioterapeuta, istodobno povećavajući učinkovitost rehabilitacijskog programa istovremeno. ${ }^{20} \mathrm{Uz}$ to može se zaključiti, nakon pregleda radova, da trenutačni broj istraživanja nije dovoljan za definitivni zaključak koji može govoriti za suvremene tehnologije ili protiv njih. To se može zaključiti i zbog malog broja istraživanja koja postoje na tu temu, a koja imaju suprotne zaključke o benefitu suvremenih tehnologija. Ono što bi trebala biti nit vodilja za daljnja istraživanja jest promjena pitanja od „Pomaže li suvremena tehnologija?” u pitanja „Kod koje dijagnoze, u kojoj fazi rehabilitacije, kojim doziranjem, kojim dobnim skupinama suvremene tehnologije mogu pomoći?"

\section{Referencije}

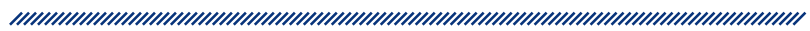

1. Peppen R. Towards evidence-based physiotherapy for stroke patients. Utrecht University \& Hogeschool Utrecht, 2008.

2. Jorgensen HS, Nakayama H, Raaschou HO, Olsen TS. Recovery of walking function in stroke patients: the Copenhagen stroke study. Arch Phys Med Rehabil. 1995; 27-32.

3. Fisher S, Lucas L, Thrasher TA. Robot-Assisted Gait Training for Patients with Hemiparesis Due to Stroke. Top Stroke Rehabil. 2011; 269-276.

4. Kubota S, Nakata Y, Eguchi K, Kawamoto H, Kamibayashi K, Sakane M, Sankai Y, Ochiai N. Feasibility of rehabilitation training with a newly developed wearable robot for patients with limited mobility. Arch Phys Med Rehabil. 2013; 1080-1087.

5. Jezernik S, Colombo G, Keller T, Frueh H, MorariM. Robotic orthosis lokomat: a rehabilitation and research tool. Neuromodulation: Technology at the Neural Interface. 2003; 108-115.
6. Wallard L, Dietrich G, Kerlirzin Y, Bredin J. Effects of robotic gait rehabilitation on biomechanical parameters in the chronic hemiplegic patients. Neurophysiologie Clinique/Clinical Neurophysiology. 2015; 215-219.

7. Laufer Y, Dickstein R, Chefez Y, Marcovitz E. The effect of treadmill training on the ambulation of stroke survivors in the early stages of rehabilitation: a randomized study. J Rehabil Res Dev. 2001; 69-78.

8. Hesse S. Treadmill training with partial body weight support after stroke: a review. NeuroRehabilitation. 2008; 55-65.

9. Hidler J, Nichols D, Pelliccio M, Brady K, Campbell DD, Kahn JH, Hornby TG. Multicenter randomized clinical trial evaluating the effectiveness of the Lokomat in subacute stroke. Neurorehabil Neural Repair. 2009; 5-13.

10. Salbach NM, Mayo NE, Higgins J, Ahmed S, Finch LE, Richards CL. Responsiveness and predictability of gait speed and other disability measures in acute stroke. Arch Phys Med Rehabil. 2011; 1204-1212.

11. Berg KO, Wood-Dauphinee SL, Williams JI, Maki B. Measuring balance in the elderly: preliminary development of an instrument. Can J Public Health. 1992; 7-11.

12. Hidler J, Wisman W, Neckel N. Kinematic trajectories while walking within the Lokomat robotic gait-orthosis. Clin Biomech. 2008.

13. Donelan JM, Shipman DW, Kram R, Kuo AD. Mechanical and metabolic requirements for active lateral stabilization in human walking. J Biomech. 2008; 827-835.

14. Regnaux JP, Saremi K, Marehbian J, Bussel B, Dobkin BH. An accelerometry based comparison of 2 robotic assistive devices for treadmill training of gait. Neurorehabil Neural Repair. 2007; 348-354.

15. Dobkin B, Apple D, Barbeau H, Basso M, Behrman A, Deforge D, Ditunno J, Dudley G, CElashoff R, Fugate L, Harkema S, Saulino M, Scott M. Weight-supported treadmill vs over-ground training for walking after acute incomplete SCI. Neurology. 2006; 484-493.

16. Morone G, Bragoni M, losa M, De Angelis D, Venturiero V, Coiro P, Pratesi L, Paolucci S. Who May Benefit From Robotic-Assisted Gait Training?: A Randomized Clinical Trial in Patients With Subacute Stroke. Neurorehabil Neural Repair. 2011; 25.

17. Mehrholz J, Pohl M. Electromechanical-assisted gait training after stroke: a systematic review comparing endeffector and exoskeleton devices. J Rehabil Med. 2012; 193-199.

18. Hornby TG, Campbell DD, Kahn JH, Demott T, Moore $\mathrm{JL}$, Roth HR.Enhanced gait-related improvements after therapist- versus robotic-assisted locomotor training in subjects with chronic stroke: a randomized controlled study. Stroke. 2008; 1786-1792.

19. Morone G, Masiero S, Werner C, Paolucci S. Advances in neuromotor stroke rehabilitation. Biomeh Res Int. 2014.

20. Kahn LE, Lum PS, Rymer WZ, Reinkensmeyer DJ. Robotassisted movement training for the stroke-impaired arm: does it matter what the robot does? J Rehabil Res Dev. 2006; 619-630. 


\section{ROBOTICS AND NEUROPHYSIOTHERAPY AFTER STROKE}

1 Lana Erjavec

1 Kristina Delaš

1 Gordana Grozdek Čovčić

1 Mirjana Telebuh

1 University of Applied Health Sciences, Zagreb

\section{Abstract

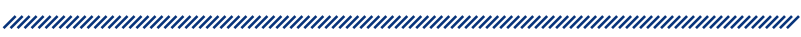

Most studies on robotics in neurorehabilitation focus on its effectiveness but they provide controversial results. Research suggests that post-stroke patients who receive robot-assisted walking therapy in combination with physiotherapy achieve walking more easily than those who did not undergo robot-assisted therapy. However, some clinical trials support manual therapy.

Critics of new technology approaches point out insufficient research on the effectiveness of robotic devices, high cost, low level of education of therapists working with such devices, poor availability, and lack of safety with some models. Research shows that robots and other technological devices that enable faster body movement do not achieve the targeted effect without a specialist physiotherapist in their specific field. On the other hand, the motivation of patients, possibility of movement repetition, shorter duration of therapy, dynamics, ability to modify various parameters, objectivity and great potential for further development are the advantages of modern technologies.
Robots, as well as all other technological devices, should be viewed as tools in the hands of physiotherapists. The robot can alleviate all intense phases of physical rehabilitation, allowing the physiotherapist to focus on functional rehabilitation in the course of individual training, as well as on monitoring several patients simultaneously during robot-assisted therapy. This approach optimizes the physiotherapist's expertise and time, increasing the effectiveness of the rehabilitation program at the same time. Current research is not sufficient for a definitive conclusion that may be inclined towards or against modern technology, but in combined use with manual therapy it can contribute to a faster recovery of the function and greater quality of the life of the patient.

Keywords: stroke, rehabilitation, modern technology, robotics 